\title{
High Undescended Testis Treatment with Distal Espermatic Vessel Ligation (Koff-Sethi Technique)
}

\author{
Carlos A. F. Molina*, Andrey G. Estevanato, Marcelo F. Cassini, Murilo F. Andrade, \\ Silvio Tucci \\ Division of Urology, Department of Surgery and Anatomy, Faculty of Medicine of Ribeirão Preto, \\ University of São Paulo, São Paulo, Brazil \\ Email: * molina@fmrp.usp.br, andreyestevanato@yahoo.com.br, marcelo.cassini@globo.com, \\ murilo.uro@gmail.com.br, stucci49@gmail.com
}

Received 17 April 2014; revised 15 May 2014; accepted 23 May 2014

Copyright (C) 2014 by authors and Scientific Research Publishing Inc.

This work is licensed under the Creative Commons Attribution International License (CC BY).

http://creativecommons.org/licenses/by/4.0/

(c) (i) Open Access

\section{Abstract}

Objectives: To evaluate the results obtained with the technique of distal spermatic vessel ligation in children with upper or intra-abdominal undescended testis. Methods: Analysis of cryptorchid patients treated with Koff-Sethi technique for orquiopexy. Patient series: 15 children with uni- or bilateral cryptorchidism. Postoperative gonad viability was evaluated on the basis of clinical data, physical examination and testicular scintigraphy. Results: Mean age was 5.4 years. Cryptorchidism was unilateral in 10/15 (67\%) patients and bilateral in 5/15 (33\%). The total number of testicles operated was 25 . Of these, $19 / 25(76 \%)$ required ligation of the spermatic vessels performed according to the Koff-Sethi technique. Eighteen $(98 \%)$ gonads remained well positioned in the scrotum and one remained in a high position. Late evaluation revealed that 14/19 (74\%) testicles had normal consistency and volume upon palpation and 3/19 (16\%) were atrophic. Two patients did not return for late reevaluation. Scintigraphy demonstrated good testicular perfusion in 14/17 $(82 \%)$ gonads evaluated. The patient with bilateral ligation of the spermatic vessels had good perfusion in both gonads. Conclusions: Distal spermatic vessel ligation (Koff-Sethi technique) is safe and useful for the treatment of high cryptorchid testicles.

\section{Keywords}

Cryptorchidism, Orchiopexy, Ischemia, Reperfusion

\footnotetext{
${ }^{*}$ Corresponding author.
}

How to cite this paper: Molina, C.A.F., Estevanato, A.G., Cassini, M.F., Andrade, M.F. and Tucci, S. (2014) High Undescended Testis Treatment with Distal Espermatic Vessel Ligation (Koff-Sethi Technique). Surgical Science, 5, 258-263. 


\section{Introduction}

At present days, guidelines recommend that undescended testis be treated preferentially during the first year of life, and the main reason for an early diagnosis and treatment of uni- or bilateral cryptorchidism is the preservation of future fertility. This has been confirmed by studies showing improvement of both testicular volume and sperm count in children operated before two years of age [1]-[3]. Patients who underwent treatment for bilateral undescended testis have a reduced fertility potential when compared to patients with unilateral orchiopexy, as confirmed by Trsinar and Muravec [4]. Another clinical problem linked to cryptorchidism is the incidence of testicular tumors, considered to be 5 to 10 times higher than in the general population [5].

Although hormonal treatment is still used by some pediatric urologists as an initial treatment for cryptorchid testis, there are potential adverse effects. The effectiveness is low and the costs are a major concern in our country. Currently, the use of hormones to treat undescended testis is not being recommended [6] [7].

The current recommendation is to perform surgical treatment during the second semester of life, at age of 6 12 months, preferably close to six months of age [8]-[13]. In parallel to the standard technique of inguinal orchiopexy through an open inguinal route, there is the possibility of the use of videolaparoscopy.

For the treatment of testicles in a high position in the abdominal cavity and with short spermatic vessels, Fowler and Stephens, in 1959, published the amply diffused technique of ligation of the spermatic vessels [14]. In this procedure, the ligation is performed at a distance from the testicle, either by videolaparoscopy or by the open route, in order to stimulate the development of collateral circulation, permitting the positioning of the gonad in the scrotum.

More recently, in 1996, Koff and Sethi published an alternative technique to the Fowler-Stephens one in which they performed ligation of the spermatic vessels close to the testis [15].

We report here the results obtained with the Koff and Sethi technique in 15 children with high undescended testis.

\section{Methods}

Analysis of follow-up of cryptorchid patients treated with Koff-Sethi orquiopexy technique.

Patients Series consisted of 15 children with uni- or bilateral cryptorchidism followed up at the Pediatric Urology Outpatient Clinic in our Institution and submitted to orchiopexy by the technique of Koff and Sethi, an open one-stage procedure, from February 1998 to July 2006.

The postoperative viability of the gonads was evaluated on the basis of clinical data, physical examination and testicular scintigraphy.

\section{Results}

Mean patient age was 5 years and 4 months and median age was 5 years and 3 months (range: 1 to 12 years). 10/15 (67\%) patients studied had bilateral cryptorchidism and the other 5/15 (33\%) had cryptorchidism on the left, for a total of 25 testicles operated.

Of the gonads that required ligation of the spermatic vessels $(n=19), 4 / 19(21 \%)$ were not palpable, 14/19 (74\%) were positioned in the internal inguinal ring and 1/19 (5\%) in the external ring. Bilateral ligation of the spermatic vessels was necessary in 1/15 (7\%) patient. Immediately after vascular ligation, 16/19 (84\%) gonads maintained good blood perfusion and 3/19 (16\%) showed signs of hypoperfusion.

Of the 19/25 (76\%) testicles with vascular ligation, 18 (98\%) remained well positioned in the scrotum and 1 (2\%) remained in a high position in the scrotum.

On late postoperative evaluation (6 months), 14/19 (74\%) testicles presented normal consistency and volumes upon palpation and 3/19 (16\%) were atrophic. Two patients did not return for late re-evaluation.

Testicular scintigraphy is a highly specific modality used to examine blood supply of testis. Imaging was performed with Low Energy General Purpose (LEGP) collimator, after intravenous administration of Tc-99m. Dynamic perfusion images were obtained each 2 seconds by 1 minute, followed by static image 5 minutes later. Testicular scintigraphy done at late postoperative evaluation, demonstrated good testicular perfusion in 14 (82\%) of the 17 gonads evaluated. Patients with bilateral ligation of the spermatic vessels, perfusion was good in both gonads.

Of the 6/25 (24\%) testicles operated without vascular ligation, 3/6 (50\%) remained positioned in the scrotum 
and 3/6 (50\%) in the external inguinal ring (Table 1).

\section{Comments}

Cryptorchidism is best clinically diagnosed during the first days of life, and treated by surgical orchiopexy before the age of one year. However, the treatment of high or intra-abdominal cryptorchid testes is a challenge for pediatric urologists and requires familiarity with alternative techniques since during orchiopexy the testicular artery and vein may limit the mobilization of the gonad to the scrotum. Section of the testicular vessels for the treatment of high cryptorchid testicles has become popular since 1959 with the definition of the criteria for the ligation of these vessels by Fowler and Stephens [14].

The testicle receives its arterial blood supply from three sources: testicular, cremasteric and deferential arteries. The above authors considered the testicular artery to be terminal and that its section immediately before the entry into the testicular parenchyma would cause ischemic atrophy of the gonad. Since the spermatic artery receives collateral vessels from the cremasteric and epididymal arteries, they recommended high ligation of the spermatic artery, as distant as possible from the testicle, thus maximizing the collateral blood supply with the flow from the spermatic and cremasteric arteries to the deferential artery.

The technique of Fowler and Stephens is frequently cited in the literature, with high success rates. Kaya et al. [16] reported that 21/24 (88\%) testicles presented normal consistency and position after surgery, with atrophy occurring in 3/24 (12\%) gonads after 3 months. Esposito et al. [17] reported practically similar results in 12 children (14 testicles), with 10/12 (83\%) viable gonads and 2/12 (17\%) atrophic ones.

When section of the spermatic vessels by the technique of Fowler-Stephens is performed in one or two stages, the results favor the latter technique. Elyas et al. [18] reported 80\% and $85 \%$ success rate for one and two stages, respectively, while Stec et al. [19] reported lower success rates of $63 \%$ and $67.6 \%$ for one and two stages, respectively.

On the other hand, Daher at al [20] contraindicated the section of the spermatic vessels during orchiopexy in non-palpable intra-abdominal testicles and reported 100\% resolution in 23 children (28 testicles) operated on and followed up for 6 months, by fixing the testis to the scrotum by 2 absorbable stitches even if there was an upward retraction of the scrotal skin. Location and size of testes were reported at 1 week, 1 month, 3 months, and 6 months through physical examination. Along this same line, Dessanti et al. [21] reported the results of orchiopexy in two stages in 38 patients (45 gonads) with intra-abdominal testicles or testicles located close to the

Table 1. Koff and Sethi technique feasibility and postoperative outcome.

\begin{tabular}{|c|c|c|c|}
\hline \multicolumn{2}{|l|}{ Variables } & \multicolumn{2}{|c|}{ Numbers } \\
\hline \multirow{3}{*}{ Cryptorchidism } & Bilateral & \multirow{3}{*}{25} & 10 \\
\hline & Right & & 05 \\
\hline & Left & & 10 \\
\hline \multirow{3}{*}{$\begin{array}{l}\text { Gonads required ligation of spermatic } \\
\text { vessels/original position }\end{array}$} & Intra abdominal & \multirow{3}{*}{19} & 04 \\
\hline & Internal Inguinal Ring & & 14 \\
\hline & External Inguinal Ring & & 01 \\
\hline \multirow{3}{*}{ Testes position after vessels ligation } & Scrotum & \multirow{3}{*}{19} & 18 \\
\hline & & & \\
\hline & High position in scrotum & & 01 \\
\hline \multirow{3}{*}{ Testes blood supply } & Good & \multirow{3}{*}{19} & 14 \\
\hline & Not good & & 03 \\
\hline & Missed follow up & & 02 \\
\hline \multirow{3}{*}{ Testes postoperative evaluation with 6 months } & Normal and Topic & \multirow{3}{*}{19} & 14 \\
\hline & Atrophic & & 03 \\
\hline & Missed follow up & & 02 \\
\hline
\end{tabular}


internal inguinal ring, without ligation of the spermatic vessels. After 1 to 8 years of follow-up, all testicles were in a satisfactory position in the scrotum (Table 2).

The technique used by Koff and Sethi is based on later studies of testicular vessels showing the existence of collateral branches between the spermatic artery and the vas deferens artery which communicate in the lower pole of the testicle, perfusing the gonad from this site. On the basis of these findings, in 1996 these authors published the technique of testicular vessel ligation to the upper pole of the testicle.

As reported by the authors, it is important to preserve the peritoneal fascia between the spermatic vessels and the vas deferens, the site of communicating branches between arterial branches. This technique is particularly useful for patients whose vas deferens forms a loop even though the testicle is in a high position. After ligation of the spermatic vessels to the upper pole of the testicle, the peritoneal fascia is incised between the loop of the vas deferens, permitting ample testicular mobilization (Figure 1). In the original article the authors reported $97 \%$ testicular viability in the first month and $93 \%$ viability after one year.

In this series, by using low spermatic vessel ligation it was possible to position the testes in the scrotum in $98 \%$ of cases. At late evaluation performed at least 6 months after surgery, $82 \%$ of the testicles showed normal consistency, were well positioned in the scrotum and presented good perfusion upon scintigraphy.

\section{Table 2. Technical and postoperative outcome.}

\begin{tabular}{|c|c|c|c|c|}
\hline Variables & Gonads & Follow-up & Outcome & Authors \\
\hline Fixing the testes to the scrotal skin & 28 & 6 months & $100 \%$ & Daher et al., 2009 \\
\hline Two stages orchiopexy & 45 & 1 to 8 years & $100 \%$ & Dessanti et al., 2009 \\
\hline \multirow{4}{*}{$\begin{array}{l}\text { Fowler-Stephens vessels ligation } \\
\text { techinique }\end{array}$} & 24 & 10 years & $88 \%$ & K aya et al., 2006 \\
\hline & 14 & - & $83 \%$ & Esposito et al., 2009 \\
\hline & Systematic review of 1807 citations & - & $85 \%$ & Elyas et al., 2010 \\
\hline & 64 & 16 months & $67.6 \%$ & Stec et al., 2009 \\
\hline
\end{tabular}

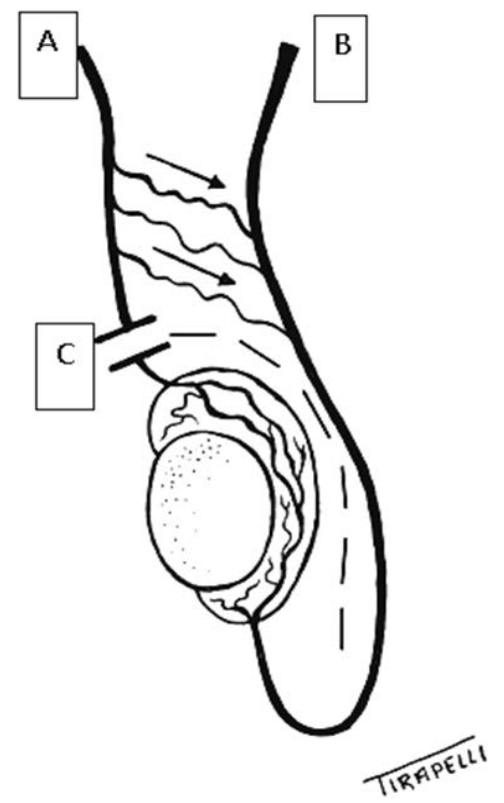

Figure 1. Koff and Sethi orchidopexy technique. Legend: A-spermatic artery; B-vas deferens; C-spermatic artery section near testicular upper pole. Arrows - collateral branches between spermatic and deferential arteries. Dashed line-incision of the peritoneal fascia. We would like to thank to Professor Luis Fernando Tirapelli for drawing the figure. 
This study was done in a public institution, and most patients with undescended testis that are referred to us are older than the ideal age for treatment. This may explain the high medium age of this series. On the other side, the attending pediatricians need to refer these patients to surgical treatment as soon as possible.

\section{Conclusion}

Early recognition of undescended testis by the attending pediatrician and its surgical treatment within the first year of life by a pediatric urologist represent the current approach to this very common anomaly of the male genitalia. Also, it is important for the attending surgeon to have different technical options during orchiopexy. Although this series have a small number of patients, but similar to other reports, we consider the Koff-Sethi technique for spermatic vessel ligation as a good and useful alternative to the Fowler-Stephens technique for the treatment of high cryptorchid testes, especially in cases with a long deferens loop. The Koff-Sethi technique permits the execution of surgery in one stage, thus avoiding reoperations.

\section{Conflict of Interest}

Nothing to declare.

\section{Financial Source}

Division of Urology, Department, Surgery and Anatomy Faculty of Medicine of Ribeirão Preto of University of São Paulo.

\section{References}

[1] Kollin, C., Karpe, B., Hesser, U., Granholm, T. and Ritzén, E.M. (2007) Surgical Treatment of Unilaterally Undescended Testes: Testicular Growth after Randomization to Orchiopexy at Age 9 Months or 3 Years. The Journal of Urology, 178, 1589-1593. http://dx.doi.org/10.1016/j.juro.2007.03.173

[2] Canavese, F., Mussa, A., Manenti, M., Cortese, M.G., Ferrero, L., Tuli, G., Macchieraldo, R. and Lala, R. (2009) Sperm Count of Young Men Surgically Treated for Cryptorchidism in the First and Second Year of Life: Fertility Is Better in Children Treated at a Younger Age. European Journal of Pediatric Surgery, 19, 388-391. http://dx.doi.org/10.1055/s-0029-1241171

[3] Chung, E. and Brock, G.B. (2011) Cryptorchidism and Its Impact on Male Fertility: A State of Art Review of Current Literature. Canadian Urological Association Journal, 5, 210-214. http://dx.doi.org/10.5489/cuaj.1010

[4] Trsinar, B. and Muravec, U.R. (2009) Fertility Potential after Unilateral and Bilateral Orchidopexy for Cryptorchidism. World Journal of Urology, 27, 513-519. http://dx.doi.org/10.1007/s00345-009-0406-0

[5] Forman, D., Pike, M.C., Davey, G., Dawson, S., Baker, K., Chilvers, C.E.D., Oliver, R.T.D. and Coupland, C.A.C. (1994) Aetiology of Testicular Cancer: Association with Congenital Abnormalities, Age at Puberty, Infertility, and Exercise. BMJ, 308, 1393-1399. http://dx.doi.org/10.1136/bmj.308.6941.1393

[6] Ludwikowski, B. and Gonzáles, R. (2013) The Controversy Regarding the Need for Hormonal Treatment in Boys with Unilateral Cryptorchidism Goes on: A Review of the Literature. European Journal of Pediatrics, 172, 5-8. http://dx.doi.org/10.1007/s00431-012-1711-y

[7] Thorsson, A.V., Christiansen, P. and Ritzén, M. (2007) Efficacy and Safety of Hormonal Treatment of Cryptorchidism: Current State of the Art. Acta Paediatrica, 96, 628-630. http://dx.doi.org/10.1111/j.1651-2227.2007.00238.x

[8] Riedmiller, H., Androulakakis, P., Beurton, D., Kocvara, R. and Gerhatz, E. (2001) EAU Guidelines on Paediatric Urology. European Urology, 40, 589-599. http://dx.doi.org/10.1159/000049841

[9] Hutson, J.M. and Hasthorpe, S. (2009) Testicular Descent and Cryptorchidism: The State of the Art in 2004. Journal of Pediatric Surgery, 40, 297-302. http://dx.doi.org/10.1016/j.jpedsurg.2004.10.033

[10] Ritzen, E.M., Bergh, A., Bierknes, R., Christiansen, P., Cortes, D., Haugen, S.E., Jorgensen, N., Kollin, C., Lindahl, S., Lackgren, G., Main, K.M., Nordenskjold, A., Raipert-De Meyts, E., Soder, O., Taskinen, S., Thorsson, A., Thorup, J., Toppari, J. and Virtanen, H. (2007) Nordic Consensus on Treatment of Undescended Testes. Acta Paediatrica, 96, 638-643. http://dx.doi.org/10.1111/j.1651-2227.2006.00159.x

[11] Murphy, F., Paran, T.S. and Puri, P. (2007) Orchidopexy and Its Impact on Fertility. Pediatric Surgery International, 23, 625-632. http://dx.doi.org/10.1007/s00383-007-1900-3

[12] Ritzen, E.M. (2008) Undescended Testes: A Consensus on Management. European Society of Endocrinology, 159, 8790. http://dx.doi.org/10.1530/EJE-08-0181 
[13] Gapany, C., Frey, P., Cachat, F., Gudinchet, F., Jichlinski, P., Meyrat, B.-J., Ramseyer, P., Theintz, G. and Bumand, B. (2008) Management of Cryptorquidism in Children: Guidelines. Swiss Medical Weekly, 138, 492-498.

[14] Fowler Jr., R. and Stephens, F.D. (1959) The Role of Testicular Vascular Anatomy in the Salvage of High Undescended Testes. Australian and New Zealand Journal of Surgery, 29, 92-106.

http://dx.doi.org/10.1111/j.1445-2197.1959.tb03826.x

[15] Koff, A.S. and Sethi, P.S. (1996) Treatment of High Undescended Testes by Low Spermatic Vessel Ligation: An Alternative to the Fowler-Stephens Technique. The Journal of Urology, 156, 799-803. http://dx.doi.org/10.1016/S0022-5347(01)65820-8

[16] Kaya, H., Cengiz, M., Orhan, T., Kendirci, M., Boylu, U. and Gumus, E. (2006) Single Stage Fowler-Stephens Orchidopexy: A Preferred Alternative in the Treatment of Nonpalpable Testes. Pediatric Surgery International, 22, 759-761. http://dx.doi.org/10.1007/s00383-006-1739-z

[17] Esposito, C., Vallone, G., Savanelli, A. and Settimi, A. (2009) Long-Term Outcome of Laparoscopic Fowler-Stephens Orchiopexy in Boys with Intra-Abdominal Testis. The Journal of Urology, 181, 1851-1856. http://dx.doi.org/10.1016/j.juro.2008.12.003

[18] Elyas, R., Guerra, L.A., Pike, J., DeCarli, C., Betolli, M., Bass, J., Chou, S., Sweeney, B., Rubin, S., Barrowman, N., Moher, D. and Leonard, M. (2010) Is Staging Beneficial for Fowler-Stephens Orchiopexy? A Systematic Review. The Journal of Urology, 183, 2012-2018. http://dx.doi.org/10.1016/j.juro.2010.01.035

[19] Stec, A.A., Stacy, T.T., Adams, M.C., John, C., Pope IV, J.C., Thomas, J.C. and Brock III, J.W. (2009) Orchiopexy for Intra-Abdominal Testes: Factors Predicting Success. The Journal of Urology, 182, 1917-1920. http://dx.doi.org/10.1016/j.juro.2009.03.069

[20] Daher, P., Nabbout, P., Feghali, J. and Riachy, E. (2009) Is the Fowler-Stephens Procedure Still Indicated for the Treatment of Nonpalpable Intraabdominal Testis? Journal of Pediatric Surgery, 44, 1999-2003. http://dx.doi.org/10.1016/j.jpedsurg.2009.06.012

[21] Dessanti, A., Falchetti, D., Iannuccelli, M., Milianti, S., Altana, C., Tanca, A.R., Ubertazzi, M., Strusi, G.P. and Fusillo, M. (2009) Cryptorchidism with Short Spermatic Vessels: Staged Orchiopexy Preserving Spermatic Vessels. The Journal of Urology, 182, 1163-1168. http://dx.doi.org/10.1016/j.juro.2009.05.050 
Scientific Research Publishing (SCIRP) is one of the largest Open Access journal publishers. It is currently publishing more than 200 open access, online, peer-reviewed journals covering a wide range of academic disciplines. SCIRP serves the worldwide academic communities and contributes to the progress and application of science with its publication.

Other selected journals from SCIRP are listed as below. Submit your manuscript to us via either submit@scirp.org or Online Submission Portal.
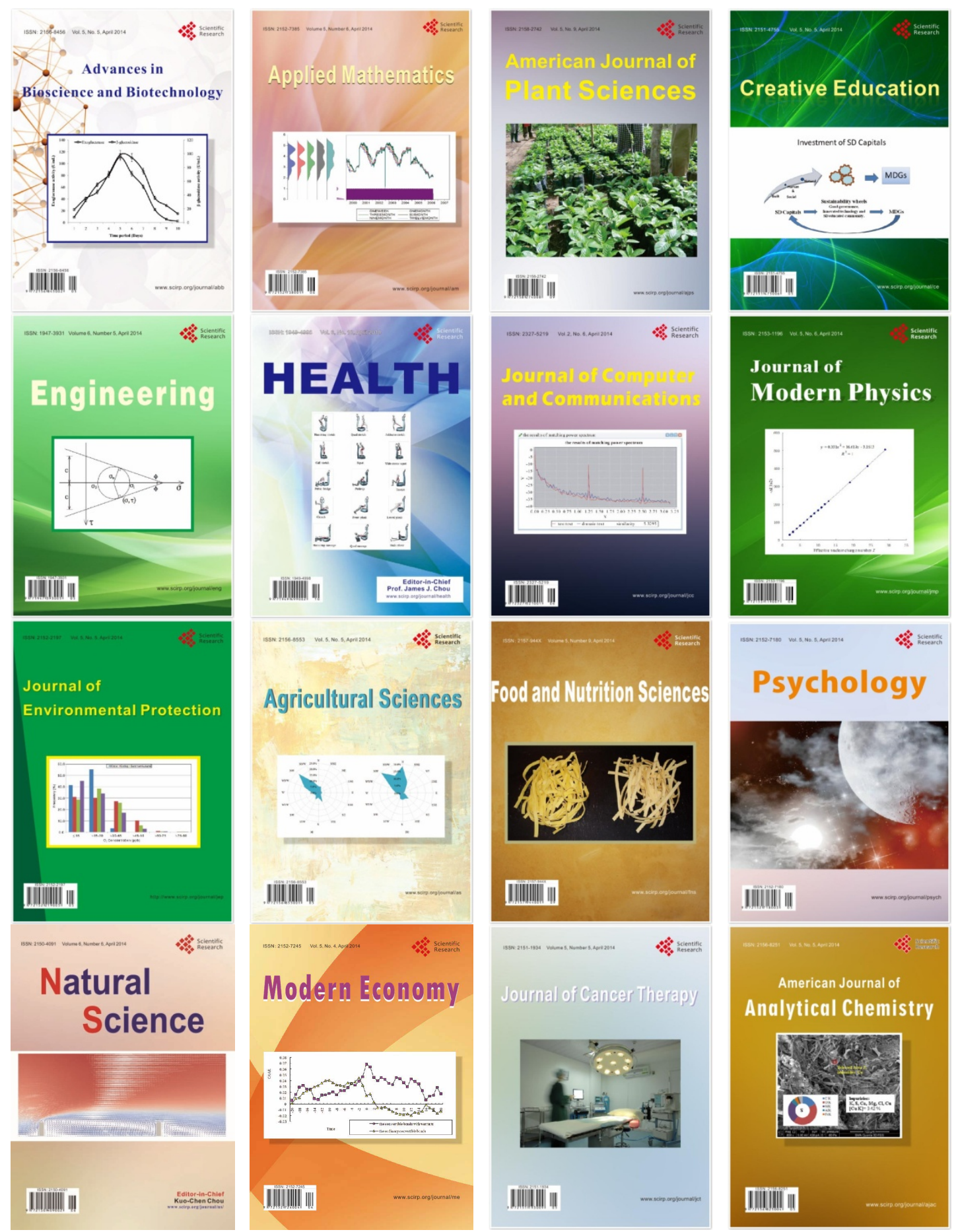